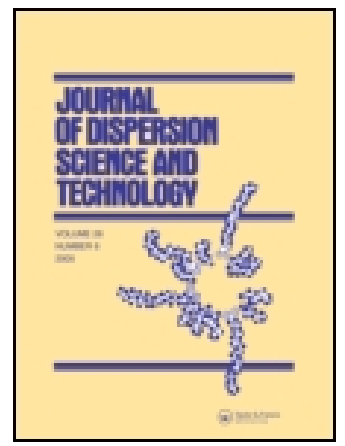

Journal of Dispersion Science and Technology

ISSN: 0193-2691 (Print) 1532-2351 (Online) Journal homepage: http://www.tandfonline.com/loi/ldis20

\title{
Adsorption of Methylene Blue from Aqueous Solution on High Lime Fly Ash: Kinetic, Equilibrium, and Thermodynamic Studies
}

\author{
Serkan Keleşoğlu , Mürşide Kes , Leman Sütçü \& Hürriyet Polat
}

To cite this article: Serkan Keleșoğlu , Mürșide Kes , Leman Sütçü \& Hürriyet Polat (2012) Adsorption of Methylene Blue from Aqueous Solution on High Lime Fly Ash: Kinetic, Equilibrium, and Thermodynamic Studies, Journal of Dispersion Science and Technology, 33:1, 15-23, DOI: 10.1080/01932691.2010.528677

To link to this article: http://dx.doi.org/10.1080/01932691.2010.528677

Accepted author version posted online: 29

Jun 2011.

Published online: 29 Jun 2011.

Submit your article to this journal 지

Џll Article views: 524

Q View related articles $\sqsubset$

4 Citing articles: 4 View citing articles 


\title{
Adsorption of Methylene Blue from Aqueous Solution on High Lime Fly Ash: Kinetic, Equilibrium, and Thermodynamic Studies
}

\author{
Serkan Keleşoğlu, ${ }^{1}$ Mürşide Kes, ${ }^{1}$ Leman Sütçü, ${ }^{2}$ and Hürriyet Polat ${ }^{1}$ \\ ${ }^{1}$ Department of Chemistry, İzmir Institute of Technology, Urla, Izmir, Turkey \\ ${ }^{2}$ Environmental Engineering Program, İzmir Institute of Technology, Urla, İzmir, Turkey
}

\begin{abstract}
Kinetic, equilibrium, and thermodynamic studies were performed for the batch adsorption of methylene blue (MB) on the high lime fly ash as a low cost adsorbent material. The studied operating variables were adsorbent amount, contact time, dye concentration, and temperature. The kinetic data were analyzed using the pseudo-first order and pseudo-second order kinetic models and the adsorption kinetic was followed well by the pseudo-second order kinetic model. The equilibrium data were fitted with the Freundlich, Langmuir, and Dubinin Radushkevich (D-R) isotherms and the equilibrium data were found to be well represented by the Freundlich and D-R isotherms. Based on these two isotherms MB is taken by chemical ion exchange and active sites on the high lime fly ash have different affinities to MB molecules. Various thermodynamic parameters such as enthalpy of adsorption $\left(\Delta H^{\circ}\right)$, free energy change $\left(\Delta G^{\circ}\right)$, and entropy change $\left(\Delta S^{\circ}\right)$ were investigated. The positive value of $\Delta H^{\circ}$ and negative value of $\Delta G^{\circ}$ indicate that the adsorption is endothermic and spontaneous. The positive value of $\Delta S^{\circ}$ shows the increased randomness at the solid-liquid interface during the adsorption. A single-stage batch adsorber was also designed based on the Freundlich isotherm for the removal of MB by the high lime fly ash.
\end{abstract}

Keywords Adsorption, equilibrium, high lime fly ash, kinetics, methylene blue, thermodynamic

\section{INTRODUCTION}

Different synthetic chemical dyes are widely utilized in many industrial processes for various purposes. Paper and pulp manufacturing, dyeing of cloth, leather treatment, and printing are frequent users of these kinds of chemicals. Most of the used solutions containing such dyes drainage as effluents. Some of these dyes are toxic in nature, so their removal from the industrial effluents is a major environmental problem. ${ }^{[1-4]}$

Biological oxidation and chemical precipitation are most commonly applied methods to remove color from dye-bearing wastewaters. However, these methods are effective and efficient when the dye concentrations are relatively high. Currently, adsorption is one of the alternative techniques to remove dyes from these kinds of wastewaters and it is basically a mass transfer process by which a substance is transferred from the liquid phase to the surface of

Received 20 August 2010; accepted 10 September 2010.

The authors would like to acknowledge Centre of Material's Research at İzmir Institute of Technology for the facilities (SEM/EDS and $x$-ray).

Address correspondence to Serkan Keleşoğlu, Department of Chemistry, İzmir Institute of Technology, Urla 35430, Izmir, Turkey. E-mail: serkan.kelesoglu@chemeng.ntnu.no a solid with physical and/or chemical interaction. ${ }^{[5-9]}$ In adsorption technology, various adsorbents such as activated carbon and clay are widely utilized to remove dyes from aqueous solutions. ${ }^{[10,11]}$ Activated carbon has excellent adsorption capacity for dyes but its uses remains limited, because of high cost. Therefore, many investigators have studied to use lower-cost and readily available adsorbents to remove dyes from aqueous solutions such as activated bleaching earth, perlite, seashells, rosewood sawdust, sugar industry pulp, sugar cane dust, tree-fern, peat moss, and natural sediment, ${ }^{[12-20]}$ as alternatives to activated carbon.

In thermal power plants, fly ash is produced in large amounts from the combustion process. Numerous studies are found in the literature about fly ash as an adsorbent material for the reason that it is abundant, inexpensive, and does not require any additional pretreatment steps. ${ }^{[21,22]}$ The focus of this research is to examine the adsorption potential of high lime Yeniköy fly ash for methylene blue (MB). In this work, MB was chosen because of its known strong adsorption onto solids and is often serves as a model compound to remove colored bodies and organic contaminants from aqueous solutions. The high lime fly ash was collected from Thermal Power Plant of Yeniköy, 
Turkey. According to our literature survey, high lime Yeniköy fly ash has not been used as an adsorbent material for the removal of dyes from water and wastewater.

In the present study, the influence of fly ash amount, initial MB concentration, contact time, and temperature on the amount of MB uptake from the aqueous solutions have been investigated. Kinetics and the mechanistic steps involved in the adsorption process were also evaluated for different $\mathrm{MB}$ concentrations. In addition, the adsorption of MB at solid liquid interfaces has been studied extensively at equilibrium and various thermodynamic parameters have been investigated.

\section{MATERIALS AND METHODS}

The fly ash sample used in this study was obtained from Thermal Power Plant of Yeniköy, Turkey. Representative ash sample were placed into a size screen analyzer (Retsch S1000) to determine size distributions of particles. The nominal particle size of the ash sample was found $100 \mu \mathrm{m}$. Particle size of the fly ash sample used in the adsorption experiments was smaller than $500 \mu \mathrm{m}$ and it was dried at $105^{\circ} \mathrm{C}$ for 2 hours before each set of experiments.

Scanning electron microscope (SEM)/energy dispersive spectroscopy (EDS) characterization of the fly ash sample was performed using a Philips XL-30S FEG type instrument. Prior to analysis, the ash sample was sprinkled onto carbon tape which is adhesive and supported on metallic disk. Images of the sample surface were recorded at different magnifications. EDS analysis was performed randomly at several different points of the surface to minimize any possible anomalies arising from the heterogeneous nature of the analyzed fly ash sample.

X-ray diffraction pattern of the fly ash sample was collected on a Philips X'Pert Pro diffractometer (Philips, Holland) using $\mathrm{Cu} \mathrm{K} \alpha$ radiation $(\lambda=0.154 \mathrm{~nm})$. Sample was prepared by compressing in the cassette sample holder without any adhesive substance.

Methylene blue (MB) with a labeled purity of more than $98 \%$ and molecular weight $373.9 \mathrm{~g} / \mathrm{mol}$ was purchased from Fluka (Germany). MB solutions were prepared by dissolving a known amount of $\mathrm{MB}$ in water at room temperature and stirred for 1 hour prior to adsorption studies. Double distilled water, which was passed through a Barnstead Easypure UV-Compact ultrapure water system (ThermoScientific, USA, $18.3 \mathrm{M} \Omega \cdot \mathrm{cm}$ ) was used to prepare all solutions.

The effect of fly ash concentration on the amount of $\mathrm{MB}$ uptake was investigated by contacting $50 \mathrm{~mL}$ of MB solution of $250 \mathrm{mg} / \mathrm{L}$ initial concentration with different weighted amount of fly ash ranging from 0.1 to $2 \mathrm{~g}$ using GFL 1083 (Germany) water bath shaker equipped with a microprocessor thermostat at $20^{\circ} \mathrm{C}$ for 2 hours, which is more sufficient time to reach equilibrium at a constant agitation speed of $250 \mathrm{rpm}$. After equilibrium, the samples were centrifuged and the concentrations of $\mathrm{MB}$ in the supernatant solutions were analyzed using Cary 50 ultraviolet-visible (UV-vis) spectrophotometer, using a $1 \mathrm{~cm}$ glass cell by monitoring the changes at a wavelength of maximum absorbance $(663 \mathrm{~nm})$.

Adsorption kinetic experiments were performed agitating the 50,150 , and $250 \mathrm{mg} / \mathrm{L}$ of $\mathrm{MB}$ concentrations with $0.25 \mathrm{~g}$ fly ash in $50 \mathrm{~mL}$ polyethylene tubes at 20,35 , and $50^{\circ} \mathrm{C}$ using water bath at a constant agitation speed of $250 \mathrm{rpm}$. The agitation times were changed from 5 to 120 minutes. The collected samples were then centrifuged and the concentration in the supernatant solution was analyzed using UV-vis spectrophotometer.

Adsorption equilibrium experiments were performed by contacting $0.25 \mathrm{~g}$ of fly ash with $50 \mathrm{~mL}$ of MB solution of different amounts, 25, 50,100,150, 200, and $250 \mathrm{mg} / \mathrm{L}$ in polyethylene tubes at 20,35 , and $50^{\circ} \mathrm{C}$ using water bath at a constant agitation speed of $250 \mathrm{rpm}$. The agitation was made for 2 hours, which is more sufficient time to reach equilibrium. The collected samples were centrifuged and analyzed as before.

In this study, all adsorption experiments were performed in duplicate and average values are reported for each condition.

\section{RESULTS AND DISCUSSION}

\subsection{Characterization of Fly Ash}

The fly ash sample was characterized to investigate its mineralogical and elemental constituents using x-ray diffraction and SEM/EDS techniques. The x-ray diffraction studies revealed the presence of portlandite, anhydrite, larnite, lime, and quartz minerals in the fly ash sample.

EDS results of the atomic percentages of $\mathrm{N}, \mathrm{O}, \mathrm{Mg}, \mathrm{Al}$, $\mathrm{Si}, \mathrm{S}, \mathrm{Ca}, \mathrm{Ti}, \mathrm{Fe}$, and molecular percentages of their oxides in the ash sample were obtained by spot analysis. Many points were randomly selected on the surface of the ash sample and mean value was calculated for each element and compound. A summary of the EDS results of the fly ash sample was given in Table 1. Surface area of the fly ash sample was also investigated by Micromeritics ASAP 2010 volumetric adsorption device employing nitrogen at a temperature of $77 \mathrm{~K}$ was also given in Table 1.

Fly ash is divided into two types namely $\mathrm{C}$ and $\mathrm{F}$ type according to ASTM C 618 standard. F type fly ash is named low lime fly ash since the quantity of $\mathrm{CaO}$ is below $10 \%$. However, C type fly ash is named high lime fly ash because the quantity of $\mathrm{CaO}$ is more than $10 \% \cdot{ }^{[23]}$ EDS results showed that the quantity of lime in the ash sample was found $55.42 \%$; this result indicates that Yeniköy fly ash is high lime (C type) fly ash.

The SEM images of the high lime fly ash sample were also given in Figure 1. The microscopic images showed that 
TABLE 1

Characteristic properties of the high lime fly ash sample

\begin{tabular}{lcccclc}
\hline Mineralogical constituents & Elements & Mass $(\%)$ & Oxides & Mass $(\%)$ & \multicolumn{2}{c}{ Physical properties } \\
\hline Larnite & $\mathrm{N}$ & 10.91 & $\mathrm{~N}_{2} \mathrm{O}_{5}$ & 14.07 & BET surface area $\left(\mathrm{m}^{2} / \mathrm{g}\right)$ & 25.2 \\
Portlandite & $\mathrm{O}$ & 57.03 & $\mathrm{MgO}$ & 2.18 & Average pore diameter $(\AA)$ & 30.1 \\
Anhydrite & $\mathrm{Mg}$ & 0.78 & $\mathrm{Al}_{2} \mathrm{O}_{3}$ & 2.13 & Pore volume $\left(\mathrm{cm}^{3} / \mathrm{g}\right)$ & 0.006 \\
Lime & $\mathrm{Al}$ & 1.51 & $\mathrm{SiO}_{2}$ & 5.11 & Nominal particle $\mathrm{size}(\mu \mathrm{m})$ & 100 \\
Quartz & $\mathrm{Si}$ & 1.81 & $\mathrm{SO}_{3}$ & 20.26 & Micropore area $\left(\mathrm{m}^{2} / \mathrm{g}\right)$ & 11.1 \\
& $\mathrm{~S}$ & 7.27 & $\mathrm{CaO}$ & 55.42 & & \\
& $\mathrm{Ca}$ & 20.11 & $\mathrm{TiO}_{2}$ & 0.06 & & \\
& $\mathrm{Ti}$ & 0.02 & $\mathrm{Fe}_{2} \mathrm{O}_{3}$ & 0.81 & & \\
& $\mathrm{Te}$ & 0.58 & & & & \\
\hline
\end{tabular}

the high lime fly ash contains porous and agglomerated particles of irregular size and shape.

\subsection{Effect of Adsorbent Amount}

The plots between amount of MB adsorbed $q_{e}(\mathrm{mg} / \mathrm{g})$ and percent MB removal against amount of fly ash mass

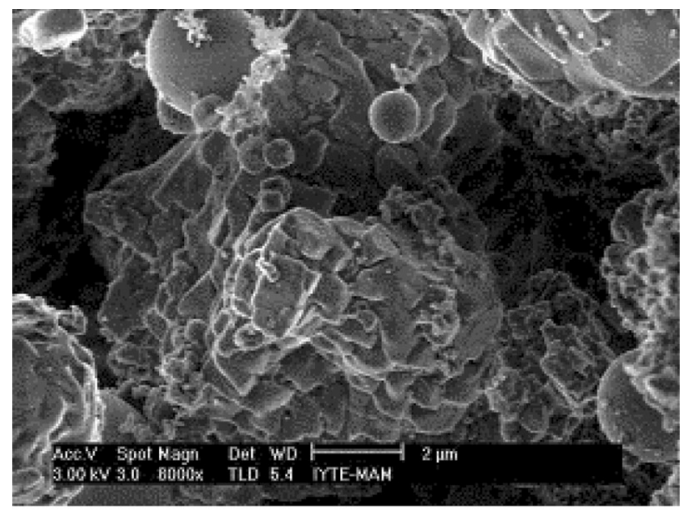

(a)

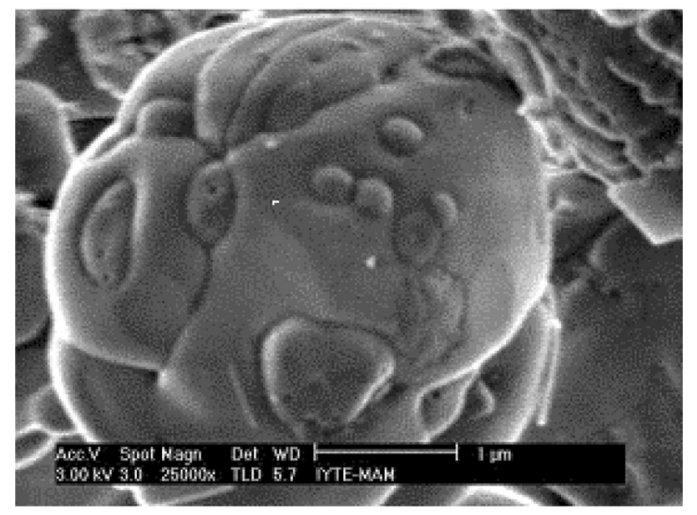

(b)

FIG. 1. SEM images of the high lime fly ash sample (a) $\times 8000$ (b) $\times 25000$. (g) were given in Figure 2, where $q_{e}$ and the percentage of $\mathrm{MB}$ removal were obtained by

$$
\begin{gathered}
\qquad q_{e}=\frac{\left(C_{0}-C_{e}\right) V}{M} \\
\text { Percent MB removal }=\left(\frac{C_{0}-C_{e}}{C_{0}}\right) \times 100,
\end{gathered}
$$

where $C_{0}(\mathrm{mg} / \mathrm{L})$ and $C_{e}(\mathrm{mg} / \mathrm{L})$ are, respectively, the concentration of $\mathrm{MB}$ in the solution at time $=0$ and at equilibrium time $t, V$ is the volume of MB solution (L), and $M$ is the amount of fly ash (g). From the Figure 2 the uptake amount of MB is varied with varying fly ash mass and it decreased with increasing in fly ash mass. The uptake amount of MB decreases from 25.83 to $6.06 \mathrm{mg} / \mathrm{g}$ for an increase in fly ash mass from 0.1 to $2 \mathrm{~g}$, whereas the percent MB removal increased from 20.66 to 96.99 . This indicates that only fixed amount of MB can be adsorbed by certain amount of fly ash. In this study the relation between the amount of $\mathrm{MB}$ adsorbed, $q_{e}$ and fly ash mass fits the

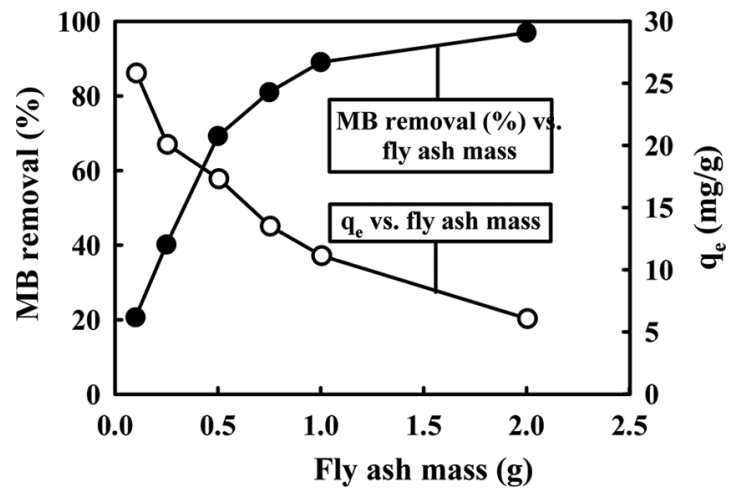

FIG. 2. Effect of the high lime fly ash amount on MB removal $\left(C_{0}=250 \mathrm{mg} / \mathrm{L}, \quad V=50 \mathrm{~mL}, \quad T=20^{\circ} \mathrm{C}, \quad \mathrm{pH}=9-10, \quad\right.$ agitation rate $=250 \mathrm{rpm})$. 
Equation (3) with a correlation coefficient; $R^{2}$ of 0.988.

$$
M=\frac{17.843-0.597 q_{e}}{q_{e}} .
$$

\subsection{Effect of Contact Time and Temperature}

The plots of the percent MB removal versus contact time for different initial $\mathrm{MB}$ concentrations of 50, 150, and $250 \mathrm{mg} / \mathrm{L}$ at 20,35 , and $50^{\circ} \mathrm{C}$ on the high lime fly ash were indicated in Figures $3 a-3 c$. From these figures it was observed that percent MB removal is increased with
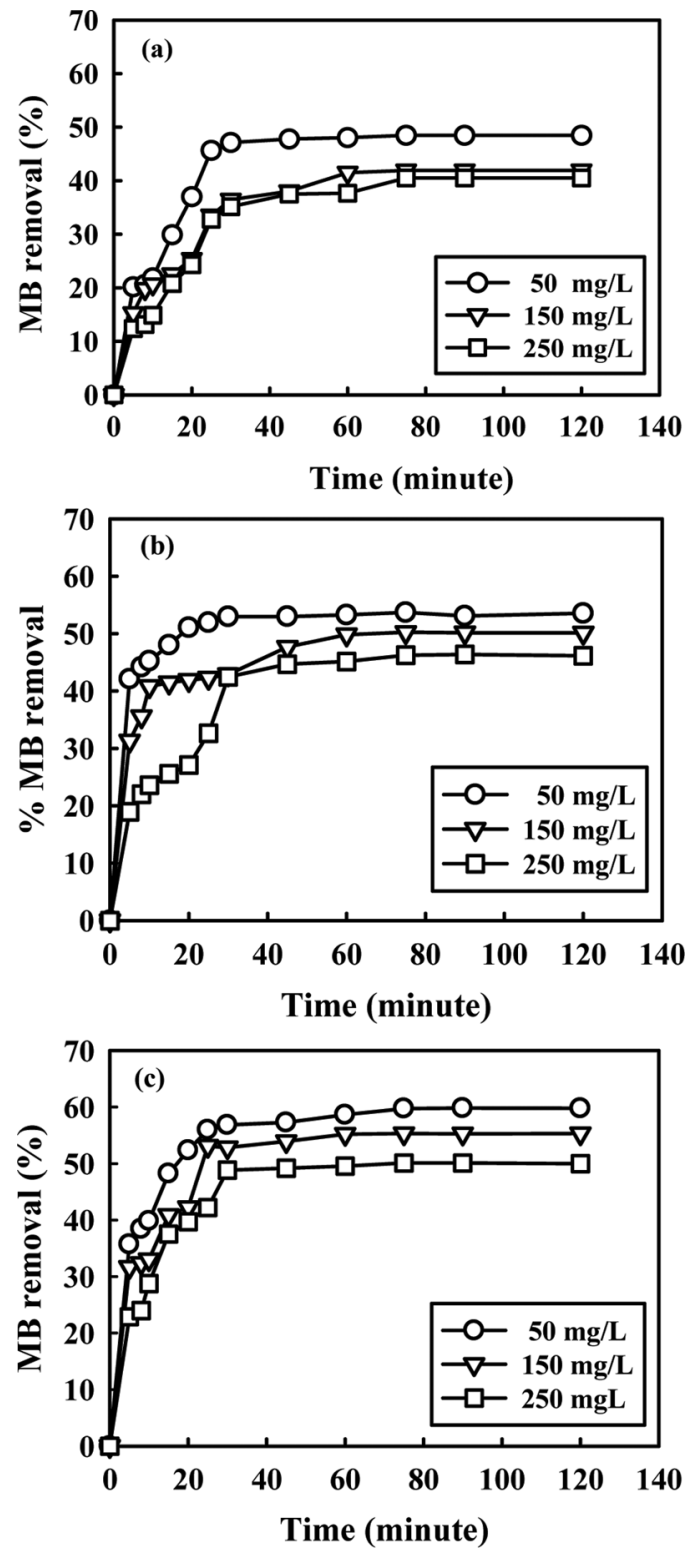

FIG. 3. Effect of contact time and temperature for the MB adsorption on the high lime fly ash. ( $V=50 \mathrm{~mL}, M=0.25 \mathrm{~g}, \mathrm{pH}=9-10$, agitation rate $=250 \mathrm{rpm}$ ) (a) $20^{\circ} \mathrm{C} \mathrm{(b)} 35^{\circ} \mathrm{C}$ (c) $50^{\circ} \mathrm{C}$. contact time and temperature for all initial MB concentrations and uptake is very rapid for the first 30 minutes for all experiments. Thereafter a gradual increase in the adsorption is seen with increasing contact time up to 60 minutes and adsorption rates were nearly stable up to 120 minutes. The higher adsorption rate at the first 30 minutes may be because of an increased number of vacant sites available at the initial stage. In addition, initial MB concentration has no effect on the equilibrium time for the MB adsorption on the high lime fly ash, so the period of 2 hours was fixed as the contact time for the equilibrium studies.

\subsection{Effect of Initial Dye Concentration}

The plots between amounts of MB adsorbed, $q_{e}$ and percent $\mathrm{MB}$ removal by high lime fly ash against initial MB concentration were given in Figure 4. From this figure it was observed that the adsorbed amount of MB increased from 2.33 to $14.01 \mathrm{mg} / \mathrm{g}$ for an increase in initial MB concentration from 25 to $250 \mathrm{mg} / \mathrm{L}$, whereas the percentage of MB removal decreases from 46.65 to $28.03 \%$. In this study the relation between amount of MB adsorbed, $q_{e}$ and initial MB concentration fits the Equation (4) with a correlation coefficient; $R^{2}$ of 0.990 as follows:

$$
q_{e}=\frac{37.43 C_{0}}{402.71+C_{0}} .
$$

\subsection{Adsorption Kinetics}

\subsubsection{The Pseudo-First Order Model}

The pseudo-first order rate equation was proposed by Lagergren ${ }^{[24]}$ and linearized form of this equation is given by

$$
\ln \left(q_{e}-q_{t}\right)=\ln q_{e}-k_{1} t
$$

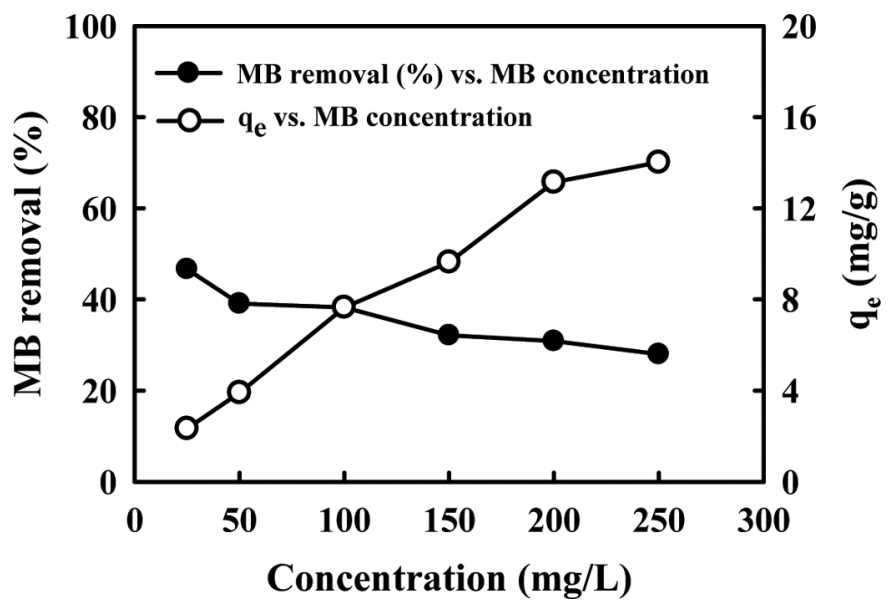

FIG. 4. Effect of initial MB concentration for the adsorption on the high lime fly ash $\left(V=50 \mathrm{~mL}, \mathrm{M}=0.25 \mathrm{~g}, T=20^{\circ} \mathrm{C}, \mathrm{pH}=9-10\right.$, agitation speed $=250 \mathrm{rpm})$. 
where $q_{t}$ and $q_{e}$ are the adsorbed amount of dye $(\mathrm{mg} / \mathrm{g})$ at time $t$ and at equilibrium time, respectively, $k_{1}$ is the pseudo-first order rate constant $\left(\mathrm{min}^{-1}\right)$. The adsorption rate constant, $k_{1}$ can be obtained by plotting of $\ln \left(q_{e}-\right.$ $q_{t}$ ) versus $t$.

The plots of $\ln \left(q_{e}-q_{t}\right)$ versus $t$ for the pseudo-first order model for the MB adsorption on the high lime fly ash were not indicated as figure because the calculated correlation coefficient; $R^{2}$ values of this model is low and ranged from 0.891 to 0.936 as seen in Table 2 . It indicates that the adsorption of $\mathrm{MB}$ on the high lime fly ash does not fit the pseudo-first order kinetic model.

\subsubsection{The Pseudo-Second Order Model}

The pseudo-second order kinetic model was also applied to experimental data of the MB adsorption on the high lime fly ash. The linearized form of this model is given by ${ }^{[25]}$

$$
\frac{t}{q_{t}}=\frac{1}{k_{2} q_{e}^{2}}+\left(\frac{1}{q_{e}}\right) t
$$

where $k_{2}(\mathrm{~g} / \mathrm{mgmin})$ is the pseudo-second order rate constant, $q_{t}(\mathrm{mg} / \mathrm{g})$ is the amount of adsorption time, $t(\mathrm{~min})$ and $q_{e}$ is the amount of adsorption equilibrium $(\mathrm{mg} / \mathrm{g})$.

This model is more likely to predict kinetic behaviour of adsorption with chemical adsorption being the rate controlling step. ${ }^{[25,26]}$ The linear plots of $t / q_{t}$ versus $t$ for 50 , 150 , and $250 \mathrm{mg} / \mathrm{L}$ of $\mathrm{MB}$ adsorption on the high lime fly ash at 20,35 , and $50^{\circ} \mathrm{C}$ were given in Figures $5 \mathrm{a}-5 \mathrm{c}$, respectively. The calculated correlation coefficients; $R^{2}$ of the pseudo-second order for the adsorption of MB on the high lime fly ash are very high and ranging from 0.988 to 0.999 . The rate constants $k_{2}, R^{2}$, and $q_{e}$ values were also given in Table 2. These results indicate that the adsorption of MB on the high lime fly ash follows well the pseudo-second order kinetic model. These results strongly suggesting a chemical reaction mechanism of MB adsorption which could occur due to the chemical character of high lime fly ash. ${ }^{[27,28]}$

\subsection{Adsorption Isotherms}

Adsorption isotherms are mathematical models, which are used to describe the distribution of the adsorbate species among solid and liquid phases. The adsorption data of MB on the high lime fly ash were investigated by using three types of the most common isotherms; Freundlich, Langmuir, and Dubinin-Radushkevich (D-R) models.

The Freundlich model can be applied to describe for non-ideal adsorption on heterogeneous surfaces and multilayer adsorption. The Freundlich model ${ }^{[2]}$ is given by

$$
\ln q_{e}=\ln K_{F}+\frac{1}{n} \ln C_{e}
$$

where $K_{\mathrm{F}}$ is the constant relating the adsorption capacity and $1 / n$ is an empirical parameter relating the adsorption intensity, which depends on heterogeneity of the material.

The Langmuir model assumes that adsorptions occur at specific homogeneous sites on the adsorbent and it is used successfully in numerous monolayer adsorption processes. The linear form of the Langmuir model ${ }^{[30]}$ is represented by

$$
\frac{C_{e}}{q_{e}}=\frac{1}{q_{m} K_{L}}+\frac{C_{e}}{q_{m}},
$$

where $q_{m}$ is the monolayer adsorption capacity of the adsorbent $(\mathrm{mg} / \mathrm{g})$ and $K_{\mathrm{L}}$ is the Langmuir constant $(\mathrm{L} / \mathrm{mg})$ relating the free energy of adsorption.

The equilibrium data were also analyzed with the Dubinin-Radushkevich (D-R) isotherm model to investigate the nature of adsorption process as physical or

\begin{tabular}{|c|c|c|c|c|c|c|c|c|}
\hline \multirow[b]{2}{*}{$C_{0}(\mathrm{mg} / \mathrm{L})$} & \multirow[b]{2}{*}{$T\left({ }^{\circ} \mathrm{C}\right)$} & \multirow[b]{2}{*}{$q_{e}$ exp. $(\mathrm{mg} / \mathrm{g})$} & \multicolumn{3}{|c|}{ Pseudo-first order } & \multicolumn{3}{|c|}{ Pseudo-second order } \\
\hline & & & $q_{\mathrm{e}, \text { calc. }}(\mathrm{mg} / \mathrm{g})$ & $k_{1}\left(\min ^{-1}\right)$ & $R^{2}$ & $q_{\mathrm{e}, \text { calc. }}(\mathrm{mg} / \mathrm{g})$ & $k_{2}(\mathrm{~g} / \mathrm{mg} \min )$ & $R^{2}$ \\
\hline \multirow[t]{3}{*}{$\overline{50}$} & 20 & 4.84 & 4.90 & $9.1 \times 10^{-2}$ & 0.919 & 5.34 & $21.1 \times 10^{-3}$ & 0.991 \\
\hline & 35 & 5.35 & 1.33 & $7.4 \times 10^{-2}$ & 0.906 & 5.43 & $12.6 \times 10^{-2}$ & 0.999 \\
\hline & 50 & 5.98 & 2.68 & $5.7 \times 10^{-2}$ & 0.914 & 6.23 & $39.9 \times 10^{-3}$ & 0.994 \\
\hline \multirow[t]{3}{*}{150} & 20 & 12.56 & 14.60 & $7.2 \times 10^{-2}$ & 0.927 & 14.21 & $5.9 \times 10^{-3}$ & 0.994 \\
\hline & 35 & 15.04 & 8.10 & $6.3 \times 10^{-2}$ & 0.891 & 15.67 & $15.4 \times 10^{-3}$ & 0.999 \\
\hline & 50 & 16.59 & 15.83 & $9.8 \times 10^{-2}$ & 0.936 & 17.61 & $10.7 \times 10^{-3}$ & 0.998 \\
\hline \multirow[t]{3}{*}{250} & 20 & 20.25 & 17.91 & $4.9 \times 10^{-2}$ & 0.912 & 23.87 & $26.1 \times 10^{-3}$ & 0.988 \\
\hline & 35 & 23.06 & 23.65 & $6.8 \times 10^{-2}$ & 0.926 & 26.04 & $3.3 \times 10^{-3}$ & 0.990 \\
\hline & 50 & 24.98 & 21.83 & $8.5 \times 10^{-2}$ & 0.919 & 26.95 & $5.5 \times 10^{-3}$ & 0.997 \\
\hline
\end{tabular}

TABLE 2

Pseudo-first order and pseudo-second order parameters for the adsorption of MB on the high lime fly ash 

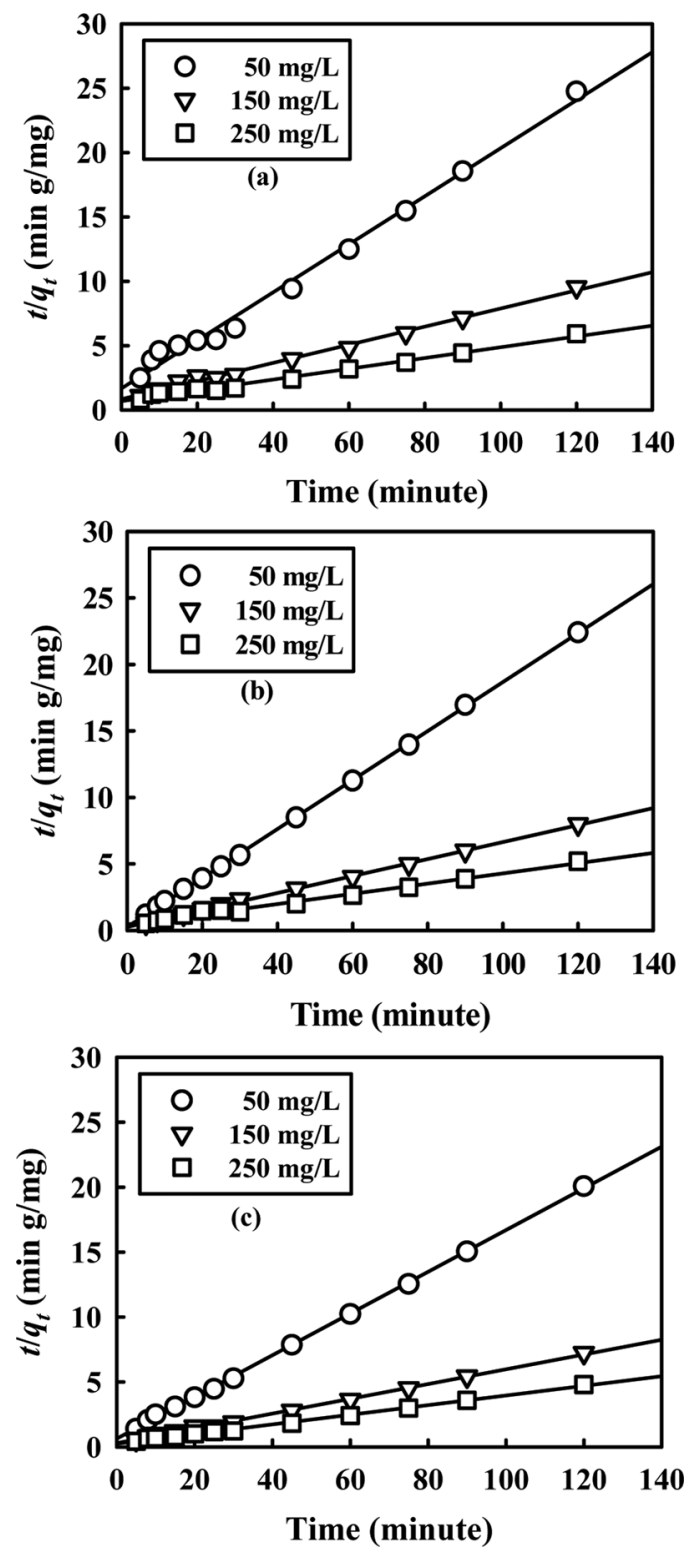

FIG. 5. Pseudo-second order kinetic plots for the MB adsorption on the high lime fly ash $(V=50 \mathrm{~mL}, M=0.25 \mathrm{~g}, \mathrm{pH}=9-10$, agitation rate $=250 \mathrm{rpm})\left(\right.$ a) $20^{\circ} \mathrm{C}$ (b) $35^{\circ} \mathrm{C}$ (c) $50^{\circ} \mathrm{C}$.

chemical. The linearized form of the $\mathrm{D}-\mathrm{R}$ isotherm equation $^{[31]}$ is given by

$$
\ln q_{e}=\ln q_{m}-\beta \varepsilon^{2},
$$

where $q_{e}$ is the amount of adsorbate on per unit weight of adsorbent $(\mathrm{mol} / \mathrm{g}), q_{m}$ is the maximum adsorption capacity $(\mathrm{mol} / \mathrm{g}), \beta$ is the activity coefficient related to mean adsorption energy $\left(\mathrm{mol}^{2} / \mathrm{J}^{2}\right)$, and $\varepsilon$ is the Polanyi potential that is defined as

$$
\varepsilon=R T \ln \left(1+\frac{1}{C_{e}}\right)
$$

The Freundlich, Langmuir, and D-R isotherms for the adsorption of $\mathrm{MB}$ on the high lime fly ash were obtained by using the linear fitting of (i) $\ln q_{e}$ versus $\ln C_{e}$ (ii) $C_{e} / q_{e}$ versus $C_{e}$ and (iii) $\ln q_{e}$ versus $\varepsilon^{2}$, respectively. Figure 6a-c shows the Freundlich, Langmuir, and D-R isotherms for the MB adsorption on the high lime fly ash. From these figures it was observed that the equilibrium data were very well represented by the Freundlich and $\mathrm{D}-\mathrm{R}$ isotherm equations when compared to Langmuir equation. The adsorption equilibrium data fit the
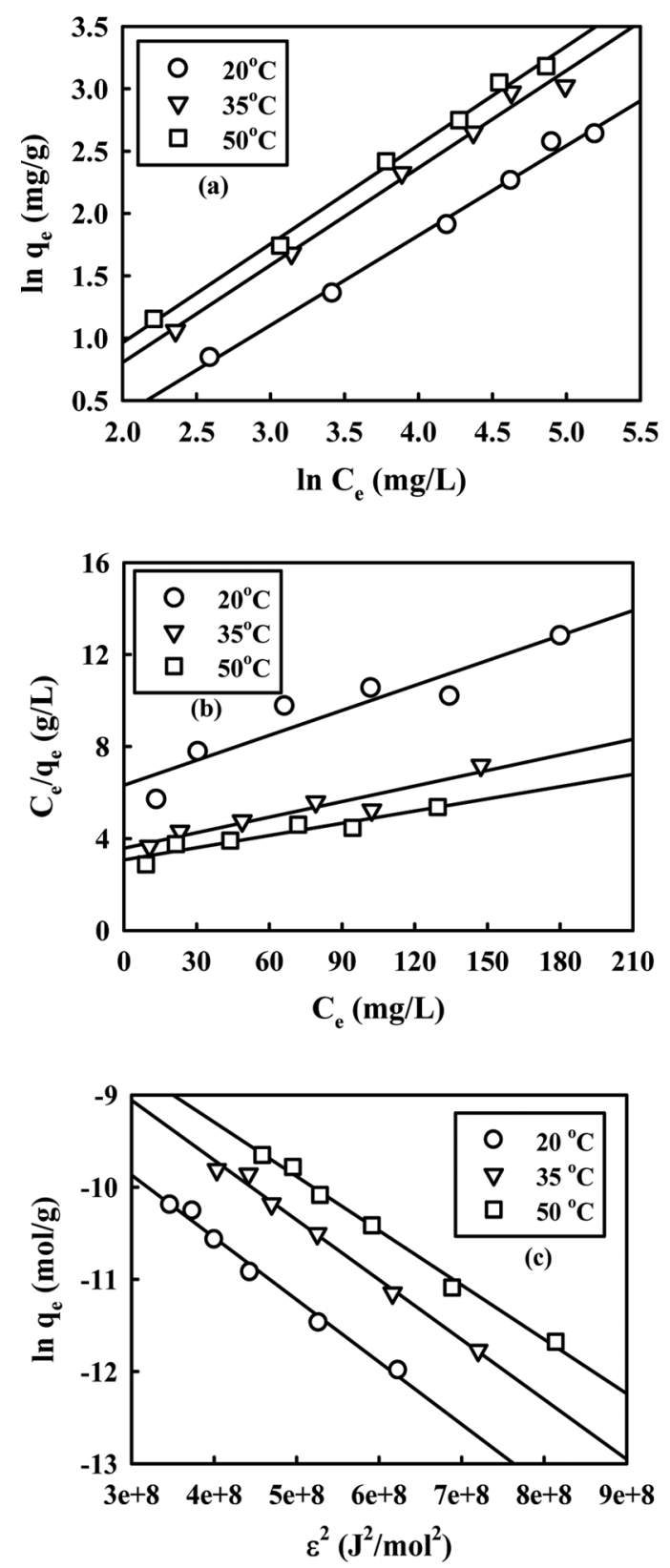

FIG. 6. Equilibrium isotherms for the adsorption of $\mathrm{MB}$ on the high lime fly ash $(V=50 \mathrm{~mL}, M=0.25 \mathrm{~g}, \mathrm{pH}=9-10$, agitation rate $=250 \mathrm{rpm})$ (a) Freundlich (b) Langmuir (c) D-R. 
Freundlich, Langmuir, and D-R isotherms with correlation coefficients; $R^{2}$ values ranging from 0.990 to 0.995 , $0.887-0.915$, and $0.990-0.994$, respectively. The calculated Freundlich, Langmuir and D-R constants and their calculated correlation coefficients at different temperatures were also given in Table 3 .

The Freundlich isotherm model is suitable to investigate the adsorption process of $\mathrm{MB}$ on the high lime fly ash in this study. The constants of Freundlich model, $K_{F}$ and 1/ $n$ were ranging from 0.348 to 0.538 and from 0.720 to 0.792 , respectively. The $1 / n$ values between 0 and 1 indicating that the adsorption of MB on the high lime fly ash was favourable at studied conditions. The high correlation coefficients values of this model indicate that the high affinity between the high lime fly ash surface and MB plays the role in the adsorption mechanism in the Freundlich model. This indicates that some heterogeneity in the surface of the high lime fly ash plays a role in adsorption process. ${ }^{[32]}$

The $\mathrm{D}-\mathrm{R}$ isotherm model also well fitted the equilibrium data because of the high correlation coefficient values. The $q_{m}$ values were found to be ranging from $3.4 \times 10^{-4}$ to $9.7 \times 10^{-4} \mathrm{~mol} / \mathrm{g}$ for the adsorption of MB on the high lime fly ash from the intercepts of the plots. The mean adsorption energy $(E ; \mathrm{kj} / \mathrm{mol})$ can be calculated as follows:

$$
E=\frac{1}{\sqrt{-2 \beta}}
$$

This adsorption potential is independent of temperature, but it varies depending on the nature of adsorbent and adsorbate. The mean free energy of adsorption gives information about adsorption mechanism as chemical ion-exchange. If $E$ value is between 8 and $16 \mathrm{kj} / \mathrm{mol}$, the adsorption process follows by chemical ion exchange and if $\mathrm{E}<8 \mathrm{kj} / \mathrm{mol}$, the adsorption process is a physical nature [33,34] The mean energy of the MB adsorption was calculated as $9.13 \mathrm{kj} / \mathrm{mol}$. This result indicates that the adsorption of $\mathrm{MB}$ on the high lime fly ash may be carried out via chemical ion-exchange mechanism.

\subsection{Adsorption Thermodynamics}

To describe the thermodynamic behaviour of the MB adsorption from aqueous solution by the high lime fly ash, the thermodynamic parameters enthalpy change $\left(\Delta H^{\circ}\right)$, entropy change $\left(\Delta S^{\circ}\right)$, and free energy change $\left(\Delta G^{\circ}\right)$ were calculated using the following equations: ${ }^{[35,36]}$

$$
\begin{gathered}
\Delta G^{\circ}=-R T \ln K_{d}, \\
\ln K_{d}=\frac{\Delta S^{\circ}}{R}-\frac{\Delta H^{\circ}}{R T}, \\
K_{d}=\frac{q_{e}}{C_{e}},
\end{gathered}
$$

where $R$ is universal gas constant and equals to $8.314 \mathrm{~J} / \mathrm{mol}$ $\mathrm{K}, T$ is the absolute temperature, and $K_{d}(\mathrm{~mL} / \mathrm{g})$ is the distribution coefficient. The distribution coefficient is an empirical equilibrium constant and it is valid at particular initial concentration and reaction conditions. ${ }^{[37]}$ The calculated values of $\Delta H^{\circ}, \Delta S^{\circ}$, and $\Delta G^{\circ}$ at different concentration of the MB adsorption on the high lime fly ash were given in Table 4 . The positive value of $\Delta H^{\circ}$ indicates the endothermic nature of the adsorption process of $\mathrm{MB}$ on the high lime fly ash. The positive value of $\Delta S^{\circ}$ shows the affinity of the high lime fly ash for $\mathrm{MB}$ and the increasing the randomness at the solid-liquid interface during the adsorption. The negative value of $\Delta G^{\circ}$ confirms the feasibility of the adsorption with a high preference of $\mathrm{MB}$ on the high lime fly ash.

\subsection{Single-Stage Batch Adsorber}

To predict the design of single-stage batch adsorption system, adsorption isotherms can be used. ${ }^{[38]}$ The schematic illustration of the single-stage batch adsorption process is indicated in Figure 7. The treated solution contains $V$ ( $L$ of water) and the dye concentration is reduced from $C_{0}$ to $C_{e}$ during the adsorption. $M$ (dye free, g adsorbent) added and the dye concentration on the high lime fly ash from $q_{0}=0$ to $q_{e}$ in the treatment stage. The mass balance that requires the dye removed from the liquid effluent to the accumulated by high lime fly ash is

$$
V\left(C_{0}-C_{e}\right)=M\left(q_{e}-q_{0}\right)=M q_{e}
$$

\begin{tabular}{|c|c|c|c|c|c|c|c|c|c|}
\hline \multirow[b]{2}{*}{ Temp. $\left({ }^{\circ} \mathrm{C}\right)$} & \multicolumn{3}{|c|}{ Freundlich isotherm parameters } & \multicolumn{3}{|c|}{ Langmuir isotherm parameters } & \multicolumn{3}{|c|}{$\mathrm{D}-\mathrm{R}$ isotherm parameters } \\
\hline & $K_{F}$ & $1 / n$ & $R^{2}$ & $K_{L}(\mathrm{~L} / \mathrm{mg})$ & $q_{m}(\mathrm{mg} / \mathrm{g})$ & $R^{2}$ & $q_{m}(\mathrm{~mol} / \mathrm{g})$ & $E(\mathrm{kj} / \mathrm{mol})$ & $R^{2}$ \\
\hline 20 & 0.348 & 0.720 & 0.993 & $5.7 \times 10^{-3}$ & 27.624 & 0.877 & $3.4 \times 10^{-4}$ & 9.12 & 0.990 \\
\hline 35 & 0.470 & 0.781 & 0.990 & $6.3 \times 10^{-3}$ & 44.248 & 0.915 & $8.2 \times 10^{-4}$ & 9.128 & 0.992 \\
\hline 50 & 0.538 & 0.792 & 0.995 & $5.8 \times 10^{-3}$ & 56.497 & 0.899 & $9.7 \times 10^{-4}$ & 9.128 & 0.994 \\
\hline
\end{tabular}

In the case of the adsorption of MB on the high lime fly ash, the Freundlich isotherm gave the best fit to the experi-

TABLE 3

Equilibrium isotherm parameters for the adsorption of MB on the high lime fly ash 
TABLE 4

Thermodynamic parameters for the adsorption of $\mathrm{MB}$ on the high lime fly ash

\begin{tabular}{lccccc}
\hline & & & \multicolumn{3}{c}{$-\Delta G^{\circ}(\mathrm{kj} / \mathrm{mol})$} \\
\cline { 4 - 6 }$C_{0}$ & $\Delta H^{\circ}$ & $\Delta S^{\circ}$ & & \multicolumn{2}{c}{} \\
\cline { 4 - 6 }$(\mathrm{mg} / \mathrm{L})$ & $(\mathrm{kj} / \mathrm{mol})$ & $(\mathrm{j} / \mathrm{mol} \mathrm{K})$ & $20^{\circ} \mathrm{C}$ & $35^{\circ} \mathrm{C}$ & $50^{\circ} \mathrm{C}$ \\
\hline 25 & 16.107 & 97.931 & 12.583 & 13.426 & 14.076 \\
50 & 11.967 & 84.227 & 12.765 & 13.276 & 13.878 \\
100 & 14.413 & 91.121 & 12.266 & 13.074 & 13.600 \\
150 & 14.244 & 90.049 & 12.115 & 12.929 & 13.433 \\
200 & 13.361 & 86.349 & 11.949 & 12.584 & 13.191 \\
250 & 10.108 & 75.433 & 11.976 & 12.560 & 12.911 \\
\hline
\end{tabular}

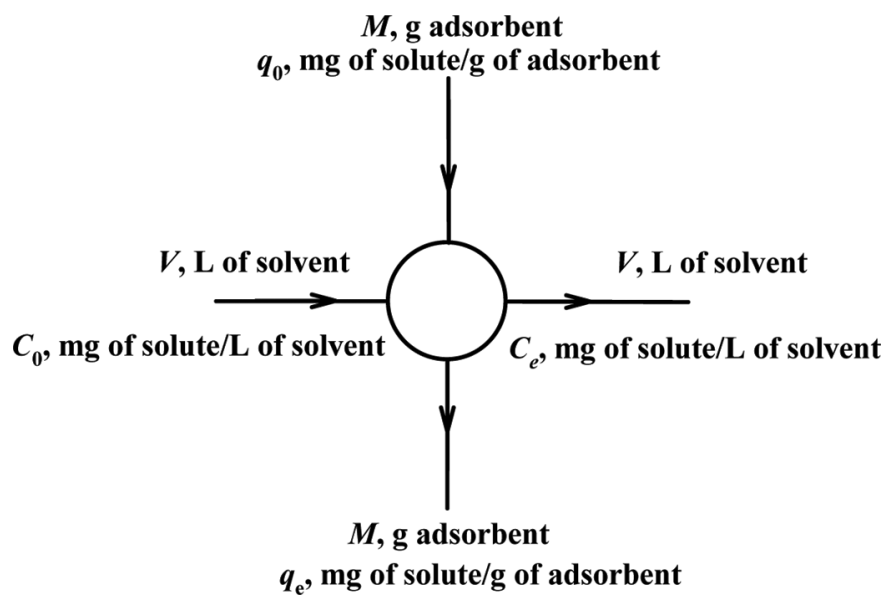

FIG. 7. A single-stage batch adsorber.

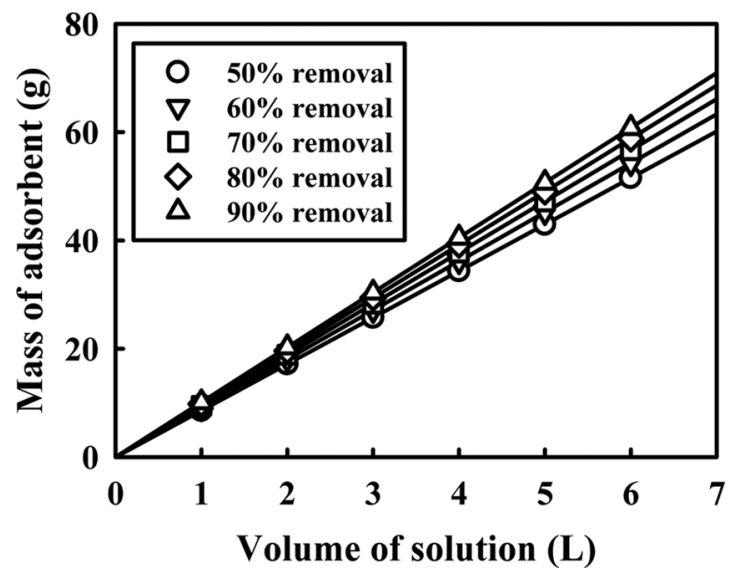

FIG. 8. Adsorbent mass $(M)$ against volume of solution $(L)$ for different percentage of MB removals by high lime fly ash $\left(C_{0}=100 \mathrm{mg} / \mathrm{L}\right.$, $\mathrm{pH}=9-10, \mathrm{~T}=20^{\circ} \mathrm{C}$ ). mental data. The Freundlich data can be applied to Equation (15) and rearrangement gives

$$
\frac{M}{V}=\frac{C_{0}-C_{e}}{q_{e}}=\frac{C_{0}-C_{e}}{K_{F} C_{e}^{1 / n}} .
$$

Analytical calculation of the adsorbent solution ratio for a given change in solution concentration from $C_{0}$ to $C_{e}$ is obtained using the Equation (16). A series of plots obtained from the Equation (16) for the adsorption of $\mathrm{MB}$ on the high lime fly ash was represented in Figure 8. An initial $\mathrm{MB}$ concentration of $100 \mathrm{mg} / \mathrm{L}$ is assumed and the figure shows the amount of effluent which can be treated to reduce the $\mathrm{MB}$ content by $90 \%, 80 \%, 70 \%, 60 \%$, and $50 \%$ using various mass of the high lime fly ash. For example, the amount of high lime fly ash required to remove $90 \%$ of $\mathrm{MB}$ solution concentration $100 \mathrm{mg} / \mathrm{L}$ was $10.13,20.26,30.39$, and $40.52 \mathrm{~g}$ for $\mathrm{MB}$ solution of 1,2 , 3 , and $4 \mathrm{~L}$, respectively.

\section{CONCLUSIONS}

In the present study the high lime fly ash as a low cost adsorbent material was used to remove methylene blue (MB) from aqueous solution. Adsorption experiments show that high lime fly ash can be used as an alternative adsorbent for the removal of $\mathrm{MB}$ from its aqueous solutions. The amount of adsorbed MB was found varying with temperature, concentration, mass of fly ash, and contact time. The amount of $\mathrm{MB}$ uptake $(\mathrm{mg} / \mathrm{g})$ was found as increasing in contact time, concentration, and temperature and decreasing with an increase in fly ash amount. The adsorption data of $\mathrm{MB}$ on the high lime fly ash well represents the pseudo-second order kinetic model and equilibrium data fitted very well with the Freundlich and Dubinin Radushkevich (D-R) isotherms. The MB uptake process was found to be controlled by chemical ion exchange and some heterogeneity in the surface of high lime fly ash plays role during the adsorption. Investigation of the thermodynamic parameters for the adsorption of MB on the high lime fly ash shows that adsorption process is endothermic, feasible, and spontaneous. The positive value of entropy $\Delta S^{\circ}$ indicates the increased randomness at the solid-liquid interface during the adsorption of $\mathrm{MB}$ on the high lime fly ash.

\section{REFERENCES}

[1] Searle, C.E. (1976) Chemical Carcinogenesis, ACS Monograph 173; Washington, DC: American Chemical Society.

[2] Zollinger, H. (1987) In Colour Chemistry; (1st ed.), edited by H.F. Ebel and C.D. Brezinger; New York: VCH, ch. 16.

[3] Ligrini, O., Oliveros, E., and Braun, A. (1993) Chem. Rev., 93: 671-698. 
[4] Helmes, C.T., Sigman, C.C., Fund, Z.A., Thompson, M.K., Voeltz, M.K., and Makie, M. (1984) J. Environ. Sci. Health A, 19: 197-231.

[5] Ho, Y.S. and McKay, G. (1998) Can. J. Chem. Eng., 76: 822826.

[6] Walker, G.M., Hansen, L., Hanna, J.A., and Allen, S.J. (2003) Water Res., 37: 2081-2089.

[7] McKay, G., Allen, S.J., McConvey, I.F., and Otterburn, M.S. (1981) J. Colloid Interface Sci., 80(2): 323-339.

[8] McKay, G. and Allen, S.J. (1980) Can. J. Chem. Eng., 58: 521-526.

[9] Kurniawan, T.A., Chan, G.Y.S., Lo, W.H., and Babel, S. (2006) Chem. Eng. J., 118: 83-98.

[10] Walker, G.M. and Weatherley, L.R. (1999) Water Res., 33: 1895-1899.

[11] Özcan, A.S. and Özcan, A. (2004) J. Colloid Interface Sci., 276: 39-46.

[12] Tsai, W.T., Chang, C.Y., Ing, C.H., and Chang, C.F. (2004) J. Colloid Interface Sci., 275: 72-78.

[13] Acemioğlu, B. (2005) Chem. Eng. J., 106: 73-81.

[14] Gulen, J., Aroguz, A.Z., and Dalgin, D. (2005) Bioresource Technol., 96: 1169-1174.

[15] Garg, V.K., Amita, A., Kumar, R., and Gupta, R. (2004) Dyes Pigm., 63: 243-250.

[16] Magdy, Y.H. and Daifullah, A.A.M. (1998) Waste Mgmt., 18: 219-226.

[17] Khattri, S.D. and Singh, M.K. (1999) Adsorpt. Sci. Technol., 17: 269-282.

[18] Ho, Y.S., Chiang, T.H., and Hsueh, Y.M. (2005) Process Biochem., 40: 119-124.

[19] Aroguz, A.Z. (2006) J. Hazard. Mater. Sci., 135 (1-3): $100-105$.

[20] Tao, Q.H. and Tang, H.X. (2004) Chemosphere, 56 (1): 31-38.
[21] Janos, P., Buchtova, H., and Ryznarova, M. (2003) Water Res., 37: 4938-4944.

[22] Diamadopoulos, E., Ionnidis, S., and Sakellaropoulos, G.P. (1993) Water Res., 27: 1773-1777.

[23] Türker, P., Erdoğan, B., Katnaş, F., and Yeğinobalı, A. (2004) Türkiye'deki Uçucu Küllerin Sınıflandırılması ve Özellikleri, Ar-Ge Enstitüsü, TÇMB, Ankara, Türkiye (in Turkish).

[24] Lagergren, S. (1898) Vetenskapsakad Handl., 24: 1-39.

[25] Ho, Y.S. and McKay, G. (1999) Process Biochem., 34: 451465.

[26] Unlü, N. and Ersoz, M. (2006) J. Hazard. Mater., 136: 272280.

[27] Ho, Y.S. and McKay, G. (1998) Chem. Eng. J., 70: 115-124.

[28] Eren, Z. and Acar, F.N. (2007) J. Hazard. Mater., 143: 226 232.

[29] Freundlich, H.M.F. (1906) J. Phys. Chem., 57: 385-470.

[30] Langmuir, I. (1918) J. Am. Chem. Soc., 40: 1361-1403.

[31] Dubinin, M.M., Zaverina, E.D., and Radushkevisch, L.V. (1947) Zhurnal Fizicheskoi Khimii, 21: 1351-1362.

[32] Wang, S., Boyjoo, B., and Choueib, A. (2005) Chemosphere, 60: 1401-1407.

[33] Lodeiro, P., Barriada, J.L., Herrero, R., and Sastre de Vicente, M.E. (2006) Environ. Pollut., 142: 264-273.

[34] Sarı, A., Tuzen, M., and Soylak, M. (2007) J. Hazard. Mater. B, 141: 258-263.

[35] Ho, Y.S. (2003) Water Res., 37: 2323-2330.

[36] Kumar, K.V. and Kumaran, A. (2005) Biochem. Eng. J., 27: 83-93.

[37] Shahwan, T., Akar, D., and Eroğlu, A.E. (2005) J. Colloid Interface Sci., 285: 9-17.

[38] McKay, G., Otterburn, M.S., and Sweeney, A.G. (1980) Water Res., 14: 21-27. 